\title{
On the Usage of the Lexemes Fathership, Fatherhood, Cousinship and Cousinhood
}

\section{Siniša Ninčević}

This paper concerns the semantic relation between the lexemes "fathership" and "fatherhood", "cousinship" and "cousinhood" in terms of their lexical properties and usage, i.e., the type of predicate the nominal base belongs to. As each of these juxtaposed pairs has the same nominal base ("father" and "cousin"), which can attach to both -ship and -hood suffixes, it is the selection of the particular suffix that can determine not only the type of predicate of the nominal base-considering the temporal spectrum in which a predicate can occur - but also the specific semantic information these lexemes can convey.

\section{KEY WORDS}

$\sim$ Suffixation

$\sim$ Nominal base

$\sim$ Lexical properties

$\sim$ Predicate

$\sim$ Specific semantic information

University of Split, Faculty of Philosophy, Sinjska 2, 21000 Split, Croatia e-mail: sinisa.nincevic@ffst.hr

\section{INTRODUCTION}

The lexemes "fathership", "fatherhood", "cousinship" and "cousinhood" have the nominal bases that are relational so their derivational output denotes that relation. These nominal bases, i.e., "father" and "cousin" can attach to both -ship and -hood suffixes. This paper will discuss these nouns both in light of the type of predicate the base belongs to and their usage in the English language. Exploring the semantics of -ship and -hood suffixations, Aronoff and Cho explain that such a derivation is based on the distinction between stage-level and individual-level predicates as predicate is an expression that is true of something in linguistic semantics.

A stage-level predicate applies to temporary properties of individuals, thus expressing unstable or transient stages (e.g. "friend"), as opposed to an individual-level predicate which pertains to lasting properties of individuals regardless of the particular point of time under consideration. They express stable properties of individuals such as in "mother" (Aronoff and Cho, 2001). The former will, in this respect, select the suffix -ship to form "friendship", whilst the latter will select the suffix -hood to form "motherhood".

What's more, Aronoff and Cho suggest yet another distinction in relation to individual-level predicates to explain the semantics of -hood derivations by means of subdividing them into left-side and right-side individual-level predicates in terms of the semantics of the nominal base as for its lexical properties in relation to the temporal spectrum - a point of time a predicate can occur - determined by the selection of a suffix. Left-side individual-level predicates (e.g. "child" - "childhood") will denote properties that individuals have at birth until a certain point in time, whereas right-side individual-level predicates will denote properties that individuals have from a certain point of time to the 
end of their lives (e.g. "mother" - "motherhood"). Thus, according to Aronoff and Cho, the suffix -ship will attach only to bases that denote transient properties as stage-level predicates as is the case with "friend(ship)", and it will not not attach to "mother" for the nominal base "mother" is a right-side individual-level predicate that expresses stable properties of individuals. Instead, "mother" will select the suffix -hood to form "motherhood".

Therefore, the suffixes -ship and -hood are state-producing nominalisers, and the suffixed nominal base is a nominalisation. The nominal bases of -ship derivations are stage-level predicates predicating unstable properties of an individual within a certain time frame (e.g."friend(ship)","companion(ship)"," president(ship)", "judge(ship)", etc.). The suffix -ship will not attach to a base the semantics of which points to lasting properties of individuals as an individual-level predicate. On the other hand, the suffix -hood will occur with individual-level predicates to express stable properties of individuals ("child(hood)", "parent(hood)", "sister(hood)", "wife(hood)", etc.).

However, although the nominalisations "mother(hood)" and "child(hood)" meet either the right-side or the left-side individual-level requirements - as for the lexical properties of these derivations - they can also be perceived as inconstant predicates in relation to the starting point $A$ and the ending point $B$ since "mother(hood)" commences at a point different from the starting point $A$ and lasts to the ending point B. "Child(hood)" occurs at the starting point $A$ but ends at a point different from the ending point B. "Daughter(hood)" is, on the other hand, a constant predicate - with respect to the type of predicate its nominal base belongs to for it denotes perpetual properties (both left and right) - which occurs at the starting point A continuing up to the ending point $B$.

Nominal bases that will select the suffix -ship are inconstant predicates for they do occur at a point different from the starting point $A$ and end at a point different from the ending point $B$. Accordingly, one can also speak of constant and inconstant predicates as for the lexical properties of the nominal base where -hood nominalisations can be both constant predicates to express perpetual properties of individuals on the condition that they occur not only at any point of time but also at each and every point of time considered, i.e., from the starting point A to the ending point B. Inconstant predicates express lasting, but not constant, properties of individuals on the condition that they occur from the starting point $A$ to a point diferrent from the ending point $B$ (left side of the temporal spectrum), as well as lasting, but not constant, properties of individuals occurring from a point different from the starting point $A$ to the ending point $B$ (right side of the temporal spectrum), i.e., occurring either on the left side or the right side of the temporal spectrum. As they occur at a point different from the starting point $A$ and end at a point different from the ending point $B$, -ship nominalisations can be perceived as inconstant center predicates as well.

\section{PERSONAL COMMON NOUNS: FATHER AND COUSIN}

What strikes the eye in the English language is the occurrence of the nominal base "father" that can attach to both suffixes, -ship and -hood, to form "fathership" and "fatherhood", as well as the occurrence of another personal common noun, i.e., "cousin" that can take both suffixes as well. Interestingly enough, the New Webster Dictionary of The English Language enters the lexemes "cousinship" and "cousinhood" as the state of being cousins, i.e., as synonyms, but omits to enter the lexeme "fathership".

Personal common nouns "father" and "cousin", whose nominal bases are relational, can take both derivational suffixes to form nominalisations that denote those relations, thus conveying the specific semantic information determined by selecting either the suffix -ship or the suffix -hood.

The selection of either -ship or -hood suffixation depends on the type of predicate the base belongs to. As these nouns have the same nominal base ("father" and "cousin") and can attach to both suffixes, it is the suffix (nominaliser) that is critical to the specific semantic information these nouns can convey as nominalisations. The occurrence of "fathership" and "cousinship" in terms of their usage are, therefore, nouns in their own right.

A couple of extracts from American and British literatures to begin by The Last of the Mohicans will contextually illustrate Aronoff and Cho's stance on the occurrence of "fathership", whilst a dialogue taken from Jane Eyre, alongside a number of selected lines from English texts, will serve to tackle the usage of "cousinship" and "cousinhood".

\section{FATHERSHIP AND FATHERHOOD}

Aronoff and Cho explain the occurrence of "fathership" as opposed to "fatherhood" (the state of being a male parent) where the suffix -hood determines the specific semantic value of the base in terms of its lexical property, i.e., as an individual-level predicate denoting lasting properties regardless of a particular point of time we consider - as the condition or state of being the oldest member of a community (Trips:168). This nominalisation ("fathership") meets the stage-level requirement as it denotes transient property of individuals, but it can also be viewed as an inconstant right predicate since it occurs at a pont different from the starting point $A$ continuing up to the ending point $B$.

In traditional societies, both past and present, it refers to an elder as an individual with a respected position due to his advanced age as exemplified in the following excerpts:

(1) "The dress of this patriarch - for such, considering his vast age, in conjunction with his affinity and influence with his people, he might very properly be termed - was rich and imposing, though strict after the simple fashions of the tribe" (Cooper: 348). 
(2) "Notwithstanding the position of the Huron, he passed the observant and silent Magua without notice, and leaning on his two venerable supporters proceeded to the high place of the multitude, where he seated himself in the center of his nation with the dignity of a monarch and the air of a father." (Cooper: 348).

The nouns "patriarch" and "monarch" along with "vast age" are followed by "the air of a father" to amplify the nature of his social attitude to others. Tamenund's father(ship) is undisputed in this social landscape. It is evident that age is of the utmost importance and determines the condition for -ship suffixation in "fathership" as it meets a stage-level requirement, i.e., a particular point of time of being the oldest member of a community as substantiated by the following lines:

(3) "They were all aged, even beyond that period to which the oldest present had reached; but one in the center, who leaned on his companions for support, had numbered an amount of years to which the human race is seldom permitted to attain." (Cooper: 347).

We are to discern father(ship) as state of being the oldest member of a community from the spiritual fathers (e.g. Father John, the Holy Father, the Church Fathers or America's Founding Fathers) for in these instances age is of no importance whatsoever (as compared with example 3). Alexander Hamilton, a Founding Father, was only 32 years old when the U.S. Constitution was signed in 1787 (DeCarolis:16). Both nouns, however, involve metaphoric quality that views venerable/spiritual/religious leaders as fathers.

\section{COUSINSHIP AND COUSINHOOD}

Inasmuch as this derivation is generally a complex linguistic phenomenon, "cousinhood" and "cousinship" stand out due to systems of degrees and removals that describe the relationship between two cousins (kinship) and the ancestor they have in common. The susceptability of the nominal base "cousin" to attaching to both suffixes can be explained by the specific semantic information that each of these derivations can convey. Namely, "cousin" is a relational noun, but in some instances it lacks the synchronicity of the "participants", such as in "cousin twice removed" or "thrice removed". "Removed", in this instance, refers to how many generations you can be separated from your cousin(s)/relatives, where, for example, "once removed" equals one generation.

Hence, the nominal base "cousin" will attach to the suffix -ship to simply express relatedness, i.e., a relationship, kinship or cousinship where, in this instance, these three -ship nouns have the same semantic value in terms of the lexical properties of the nominal base. The discovery of the existence of a genealogical link can happen at any point of time between the starting point $A$ and the ending point $B$ (example 4 ) in which case the predicate of the base meets the stage-level requirement in "cousinship".

As the degree of "first cousins" (sharing the same grandparent) meets the requirement of relational synchronicity, the nominal base will attach to the suffix -hood to express stable properties of individuals. However, in terms of the lexical properties of the base, i.e., the type of predicate the base belongs to, "cousin(hood)" can meet the individual-level requirement as both a constant predicate (occurring from the starting point $A$ continuing up to the ending point $B$ ) and an incostant predicate (occurring at a point different from the starting point $A$ ) from the younger/older cousin perspective.

In the aforementioned dialogue between Jane Eyre and Mr. Rochester, the latter asks Jane:

(4) "St. John made you school-mistress of Morton before he knew you were his cousin?" "How long did you reside with him and his sister after the cousinship was discovered?" (Brontë: 442). As the story unfolds, the reader learns of St. John and Jane's relationship/cousinship.

By extension, "cousinship" is also used to denote something similar in quality or character (Ninčević, 2009) - we can also speak of the quality or character of Jesus's sonship - or an interesting or unusual quality exemplified in an array of literary examples:

(5) "What he repudiated was cousinship with the ape, and the implied suspicion of a rudimentary tail..." (Shaw: 28).

(6) "He describes a beautiful thought experiment to demonstrate a rabbit's cousinship to a leopard." (Wade: 22).

(7) "His creed of determination was such that it almost amounted to a vice, and quite amounted, on its negative side, to a renunciative philosophy which had cousinship with that of Schopenhauer and Leopardi." (Hardy: 157).

(8) "Symmetry establishes a ridiculous and wonderful cousinship between objects, phenomena, and theories outwardly unrelated..." (Bishop: 1).

\section{CONCLUSION}

The said "cousinship" examples, save for the conversation between St. John and Jane Eyre, do not imply any family relations or reference to a member of a group of people with similar origins, be it cousins twice or thrice removed, etc. Still, the nominalisation "cousinship" is, for that matter, evidently possible in the English language and used not only to denote a cousinly relation(ship) in view of the aforementioned context - with regard to the type of predicate of the nominal base - but also to convey another piece of specific semantic information, i.e., an abstract idea of the quality of relatedness which generally covers a number of subject areas (examples 5, 6, 7, 8).

The nominal base "cousin" can also be suffixed with -hood 
to express stable properties of individuals either as a constant predicate or an inconstant predicate as for the lexical properties of the nominal base. Examples $(1,2,3)$ suggest that the lexemes "fathership" and "fatherhood" are synonymous to a certain extent for they can convey their specific semantic information in terms of the predicate of the base, respectively. Likewise, this paper has considered and viewed the temporal extent of these nominalisations from another possible perspective, and is hence open to further research.

\section{REFERENCES}

Aronoff, M., Cho, S., (2001), The Semantics of -Ship Suffixation, Linguistic Inquiry, 32(1), pp. 167-173.

doi: http://dx.doi.org/10.1162/002438901554621

Bishop, D., (1973), Group Theory and Chemistry, The Clarendon Press: Oxford.

Brontë, C., (2000), Jane Eyre, Oxford World's Classics: New York.

Carlson, G., Pelletier, F., (1995), The Generic Book: The University of Chicago Press.

Cooper, F. J., (1994), The Last of the Mohicans, Penguin Popular Classics: London
Cousinship, available at: http://www.merriam-webster.com/dictionary/cousinship, [accessed 01.06. 2012].

DeCarolis, L., (2003), Alexander Hamilton: Federalist and Founding Father, The Rosen Publishing Group: New York.

Fathership, available at: http://www.merriam-webster.com/dictionary/fathership, [accessed 1 June 2012].

Hardy, T., (1998), Tess of the d'Urbervilles. Penguin Classics: London.

Ninčević, S., (2009), Various Semantic Aspects of English -Ship Suffixation, Strani jezici 38 (3), 297-302.

Shaw, G. B., (2007), Back to Methuselah. BiblioBazaar: Charleston (SC).

McQueen, A,. Thatcher, V., The New Webster Dictionary of the English Language, Consolidated Book Publishers.

Trips, C., (2009), Lexical Semantics and Diachronic Morphology, The Development of - Hood and -Ship in the History of English, Linguistiche Arbeiten, Max Niemeyer Verlag: Tübingen.

Vendler, Z., (1957), Times and Verbs, Duke University Press, The Philosophical Review 66 (2), pp.143-160.

Wade, N., (2009), Evolution All Around, New York Times: 22. available at: http:// www.nytimes.com/2009/10/11/books/review/Wade-t.html?pagewanted=all\&_r=0 [accessed 2 June 2012]. 